\title{
Short communication: Development and evaluation of predictive models of body weight for crossbred Holstein-Zebu dairy heifers
}

\author{
A. S. Oliveira, ${ }^{1}$ D. C. Abreu, M. A. Fonseca, and P. M. B. Antoniassi \\ *Institute of Agriculture and Environmental Sciences, Federal University of Mato Grosso, Campus Sinop, Sinop, MT 78557-267, Brazil
}

\begin{abstract}
Equations to predict body weight (BW) of crossbred Holstein-Zebu dairy heifers were developed and compared with current models (Heinrichs et al. for Holsteins, United States; Reis et al. for crossbred HolsteinZebu, Brazil). The data set was constructed from 150 measurements of $\mathrm{BW}(320 \pm 107 \mathrm{~kg})$ and biometric measurements such as heart girth $(\mathrm{HG}, 161 \pm 19.5 \mathrm{~cm})$, withers height (WH, $126 \pm 11.0 \mathrm{~cm}$ ), and hip height $(\mathrm{HH}, 132 \pm 11.3 \mathrm{~cm})$ of heifers from 5 commercial dairy producers in the southern Amazon region in Brazil. The data were evaluated using mixed nonlinear models with herd as a random effect. Three nonlinear equations were fitted: $\mathrm{BW}(\mathrm{kg})=0.00058 \cdot \mathrm{HG}(\mathrm{cm})^{2.6135} ; \mathrm{BW}(\mathrm{kg})$ $=0.000618 \cdot \mathrm{HG}(\mathrm{cm})^{2.7362}$; and BW $(\mathrm{kg})=0.000196 \cdot \mathrm{HH}$ 2.8793. An independent database was constructed to evaluate the models from 38 treatment means of 4 feeding trials: BW $258 \pm 54.3 \mathrm{~kg}, \mathrm{HG} 142.5 \pm 11.8 \mathrm{~cm}, \mathrm{WH}$ $113.2 \pm 6.0 \mathrm{~cm}$, and HH $118.7 \pm 9.1 \mathrm{~cm}($ mean $\pm \mathrm{SD})$. The evaluations were based on the relationship between observed and predicted values of BW by linear regression, root mean square prediction error (RMSPE), and concordance correlation coefficient analysis. Only the proposed model using HG accurately predicted observed BW, with bias (observed - predicted) of 4.83 $\mathrm{kg}$ and RMSPE of $5.41 \%$ of observed BW (87.7\% of random error). The models using $\mathrm{WH}$ and $\mathrm{HH}$ failed to accurately predict observed BW, with a bias of -3.06 and $72.02 \mathrm{~kg}$, and RMSPE of $9.40 \%$ of observed BW (75.2\% of random error and $23.1 \%$ of systematic error) and $30.81 \%$ of observed BW ( $81.2 \%$ of mean bias). Additionally, the models of Heinrichs and Reis used for comparison did not predict BW accurately, with a bias of 19.32 and $29.37 \mathrm{~kg}$ and RMSPE of $9.08 \%$ of observed BW (68.4\% of mean bias and $31.4 \%$ of random error) and $12.58 \%$ of observed BW (81.9\% of mean bias). The largest concordance correlation coefficient of the
\end{abstract}

Received May 1, 2013.

Accepted July 4, 2013.

${ }^{1}$ Corresponding author: andresoli@ufmt.br proposed HG-nonlinear model (0.930), compared with the models of Heinrichs and Reis of 0.845 and 0.708 , confirmed the greater accuracy and precision of the new equation to predict BW in crossbred Holstein-Zebu dairy heifers.

Key words: body growth, meta-analysis, modeling

\section{Short Communication}

Body weight measurements are essential in growing systems for dairy heifers to determine nutritional requirements and feeding, breeding, health, and reproductive management. However, the adoption of BW measurement by farmers remains a challenge. Surveys performed in several dairy regions in Brazil have demonstrated that fewer than $10 \%$ of dairy farmers weigh their heifers, due to the low availability of scales on farms (Diagnóstico da Pecuária Leiteira do Estado do Minas Gerais, 2005; Diagnóstico da Cadeia Produtiva do Leite do Estado de Mato Grosso, 2011). Thus, a feasible alternative would be to provide an indirect, fast, and low-cost method able to estimate BW of heifers on commercial herds.

Biometrics measurements such as heart girth $(\mathbf{H G})$, withers height (WH), hip height $(\mathbf{H H})$, and body length represent an alternative to estimate BW (Davis et al., 1961). Some predictive equations have been developed for Holsteins in the United States (Heinrichs et al., 1992) and for crossbred Holstein-Zebu in Brazil (Reis et al., 2008) that are able to assess the BW through biometric measurements. However, these models were empirically developed, which means their accuracy and precision are population dependent. Furthermore, the models proposed by Heinrichs et al. (1992) and Reis et al. (2008) have not been evaluated using an independent data set, which could make their full acceptance and recommendation questionable.

Thus, the objectives were (1) to develop equations to predict BW of dairy crossbred Holstein-Zebu heifers through the use of biometrics measurements, and (2) to evaluate the adequacy of the proposed predictive models compared with the models of Heinrichs et al. (1992) and Reis et al. (2008) using an independent database. 
Table 1. Descriptive statistics of the data sets used to develop and evaluate model predictions of BW in dairy heifers

\begin{tabular}{lccccr}
\hline Body measurement & Mean & Minimum & Maximum & Median & SD \\
\hline Development $(\mathrm{n}=150)^{1}$ & & & & & \\
BW, kg & 319.6 & 86.0 & 605.0 & 333.0 & 107.2 \\
Heart girth, cm & 161.2 & 110.0 & 200.0 & 166.0 & 19.5 \\
Withers height, cm & 126.2 & 90.0 & 149.0 & 128.0 & 11.0 \\
Hip height, cm & 131.7 & 96.0 & 150.0 & 134.0 & 11.3 \\
Evaluation (n=38) & & & & & \\
BW, kg & 257.8 & 146.9 & 347.4 & 257.9 & 54.3 \\
Heart girth, cm & 142.5 & 118.0 & 159.6 & 143.7 & 11.8 \\
Withers height, cm & 113.2 & 100.8 & 123.2 & 113.4 & 6.0 \\
Hip height, cm & 118.7 & 116.6 & 129.6 & 113.2 & 9.1 \\
\hline
\end{tabular}

${ }^{1}$ One hundred fifty heifers in 5 herds.

${ }^{2}$ Miranda et al. (1999); Guimarães (2009); Vidaurre, (2009); Santos et al. (2010).

Table 2. Solution for fixed effects of nonlinear equations for predicting BW in crossbred and Holstein dairy heifers from body measurements ${ }^{1}$

\begin{tabular}{|c|c|c|c|c|c|c|}
\hline Model & $\begin{array}{l}\text { Biometric } \\
\text { measurement }\end{array}$ & Equation & $P$-value & $\mathrm{AIC}$ & $\mathrm{BIC}$ & $\mathrm{S}_{\mathrm{xy}}$ \\
\hline [1] & Heart girth (HG) & $\mathrm{BW}=0.00058 \cdot \mathrm{HG}^{2.6135}$ & $<0.001$ & $1,398.6$ & $1,397.0$ & 0.96 \\
\hline$[2]$ & Withers height (WH) & $\mathrm{BW}=0.000618 \cdot \mathrm{WH}^{2.7362}$ & $<0.001$ & $1,561.7$ & $1,560.1$ & 0.90 \\
\hline
\end{tabular}

${ }^{1} \mathrm{AIC}=$ Akaike information criterion; BIC $=$ Bayesian information criterion; $\mathrm{S}_{\mathrm{xy}}=$ correlation coefficient between predicted and observed values.

The data set of $\mathrm{BW}$ and biometrics measurements was obtained from 150 crossbred Holstein-Zebu dairy heifers from 5 commercial dairy herds in the south Amazon region in Brazil (Table 1). The main biometric measurements taken were $\mathrm{HG}, \mathrm{WH}$, and $\mathrm{HH}$, as described by Heinrichs and Lammers (1998).

Three nonlinear equations (allometric) were fitted in an attempt to predict $\mathrm{BW}$ from $\mathrm{HG}, \mathrm{WH}$, and $\mathrm{HH}$. Sta-

Table 3. Analysis of regression between observed (Y) and predicted (X) values of BW for various models used for Holstein and crossbred Holstein-Zebu dairy heifers

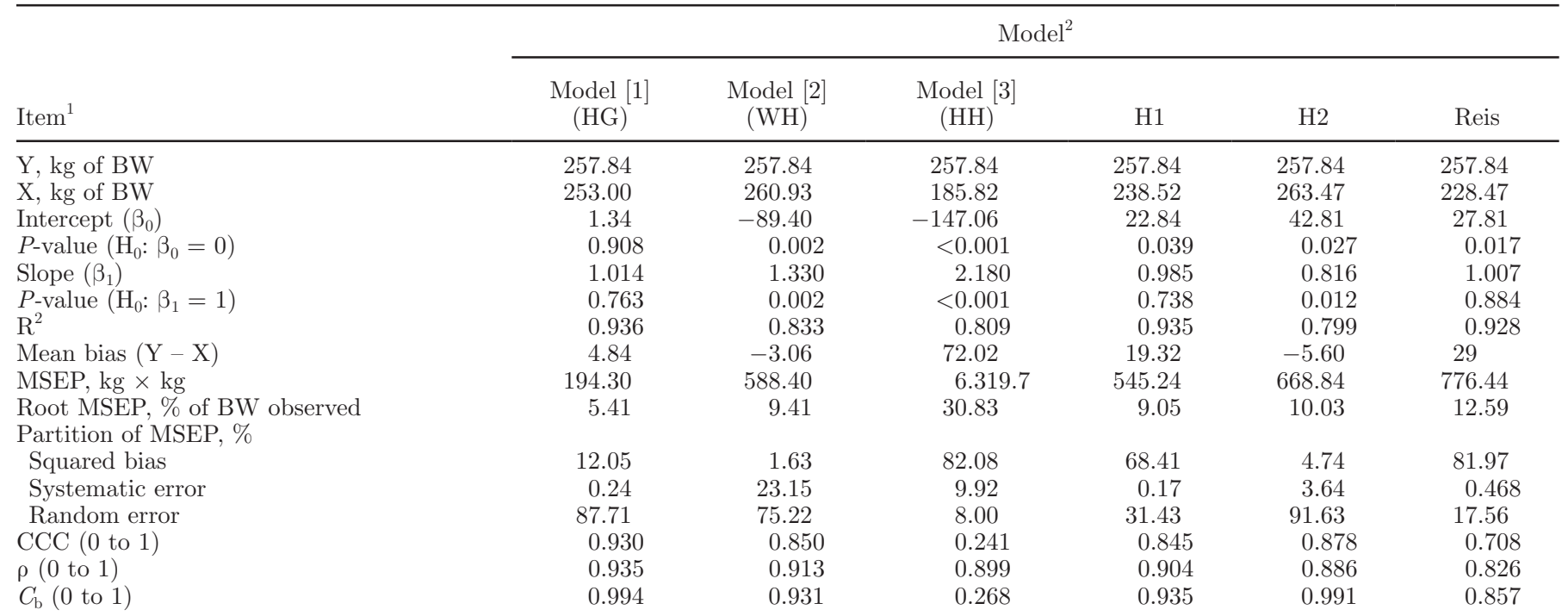

${ }^{1}$ Models [1], [2], and [3] = models in the current study using heart girth (HG), withers height (WH), and hip height (HH); H1 = model proposed by Heinrichs et al. (1992) using heart girth; H2 = model proposed by Heinrichs et al. (1992) using withers height; Reis = model proposed by Reis et al. (2008) using heart girth.

${ }^{1} \mathrm{MSEP}=$ mean squared error of prediction; $\mathrm{CCC}=$ concordance correlation coefficient; $\rho=$ correlation coefficient estimate; and $C_{\mathrm{b}}=$ bias correction factor. 
tistical analyses were performed using a mixed model as described by Littell et al. (2006), utilizing PROC NLMIXED of SAS (2000; SAS Institute Inc., Cary, $\mathrm{NC}$ ) and considering the herd as a random effect and body measurements as fixed effects:

$$
Y_{i j}=a \times B M^{b}+u_{i 1}+e_{i j}
$$

where $Y_{i j}=\mathrm{BW}$ of the $i$ th heifer in the $j$ th herd, in which $i$ ranges from 1 to 150 and $j$ ranges from 1 to 5 ; $\mathrm{BM}=$ fixed effect of biometric measurements ( $\mathrm{HG}$, $\mathrm{WH}$, or $\mathrm{HH}) ; a$ and $b=$ fixed effects parameters of the potential model; $u_{i l}=$ random effects parameters, assuming $N\left(0, \sigma_{e}^{2}\right)$; and $e_{i j}=$ random error associated with each observation, assuming $N\left(0, \sigma_{e}^{2}\right)$. Data points were removed if the studentized residual was outside the range of -2.5 to 2.5 (Neter et al., 1996). The critical level of probability for type I error was set at 0.05 .

To evaluate the adequacy of the models, an independent data set composed of 38 measurements of BW (obtained after overnight feed withdrawal) and biometric measurements (HG, WH, and $\mathrm{HH}$ ) from 4 experiments performed with crossbred Holstein-Zebu and Holstein dairy heifers was used to assess the adequacy of the proposed models (Miranda et al., 1999; Guimarães, 2009; Vidaurre, 2009; Santos et al., 2010). The BW values obtained from these animals were converted to full BW by dividing the fasted BW by 0.96 , as recommended by NRC (2001).

The proposed equations were compared with those suggested by Heinrichs et al. (1992) for Holstein dairy heifers:

$$
\begin{gathered}
\text { BW }(\mathrm{kg})=102.71-2.876(\mathrm{HG}, \mathrm{cm}) \\
+0.02655\left(\mathrm{HG}, \mathrm{cm}^{2}\right),[\mathrm{H} 1] \\
\mathrm{BW}(\mathrm{kg})=623.13-16.837(\mathrm{WH}, \mathrm{cm}) \\
\quad+0.11989\left(\mathrm{WH}, \mathrm{cm}^{2}\right),[\mathrm{H} 2]
\end{gathered}
$$

and by Reis et al. (2008) for crossbred Holstein-Zebu dairy heifers:

$$
\begin{gathered}
\text { BW }(\mathrm{kg})=1,717-35.167(\mathrm{HG}, \mathrm{cm})+0.238978 \\
\left(\mathrm{HG}, \mathrm{cm}^{2}\right)-0.00046260\left(\mathrm{HG}, \mathrm{cm}^{3}\right) .
\end{gathered}
$$

The evaluation of these models was based on the analysis of the linear regression between observed (Yaxis) and predicted values (X-axis), under the following hypotheses: null hypothesis $\left(\mathrm{H}_{0}\right): \beta_{0}=0$, alternative hypothesis $\left(\mathrm{H}_{\mathrm{A}}\right): \beta_{0} \neq 0 ; \mathrm{H}_{0}: \beta_{1}=1, \mathrm{H}_{\mathrm{A}}: \beta_{1} \neq 1$. Only in the case that both hypotheses are accepted can the
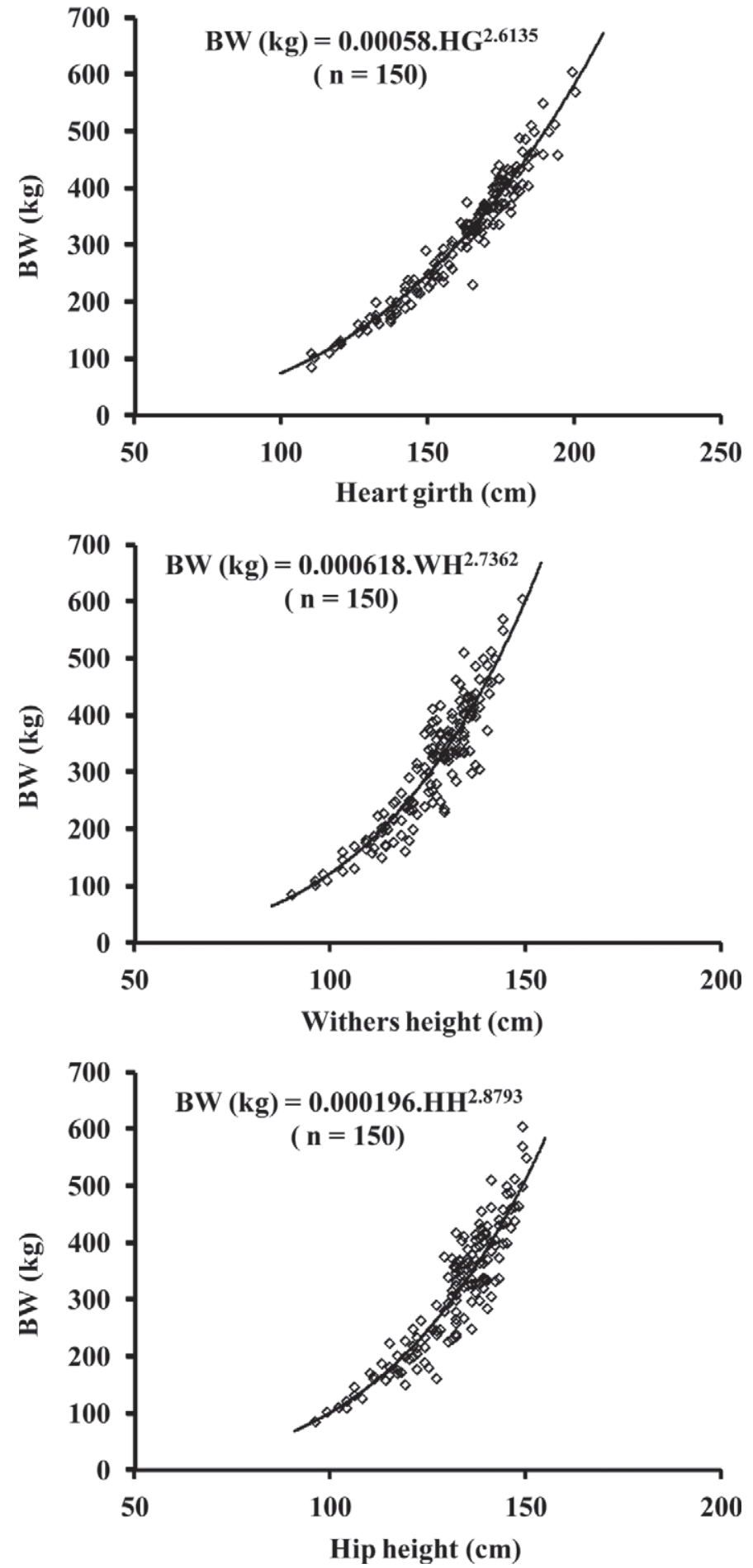

Figure 1. Relationships between BW and heart girth (HG), withers height $(\mathrm{WH})$, or hip height $(\mathrm{HH})$ for crossbred Holstein-Zebu dairy heifers. The data were obtained from 150 heifers in 5 commercial herds. The nonlinear equations were adjusted for the random effect of herd using a mixed model. 

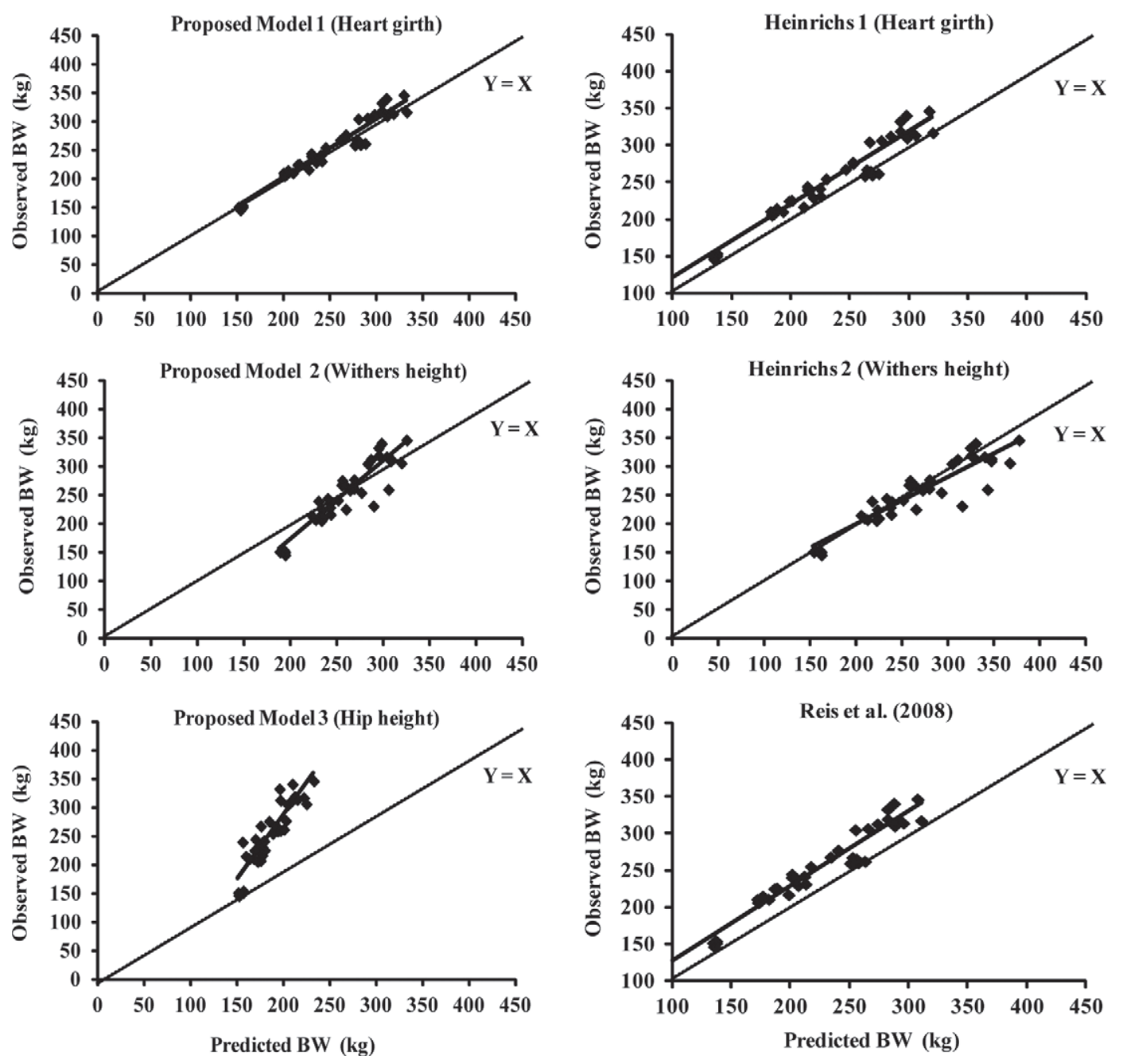

Figure 2. Relationships between observed and predicted BW using proposed models [1] (heart girth), [2] (withers height), and [3] (hip height), and models proposed by Heinrichs et al. (1992) using heart girth and withers height, and the model proposed by Reis et al. (2008) using heart girth.

model be considered a proper predictor of the observed values. The analysis of linear regression was achieved using PROC MIXED methodology (SAS Institute Inc.), with the experiment as a random effect (StPierre, 2001). Thus, 0.05 was adopted as the level of probability for type I error.

The precision and accuracy of the models were assessed by the estimate of the concordance correlation coefficient (CCC) as described by Lin (1989). The CCC was divided into correlation coefficient $(\boldsymbol{\rho})$, as the precision indicator, and bias correction factor $\left(\boldsymbol{C}_{\mathrm{b}}\right)$, as the accuracy indicator, where higher values indicate a more precise or accurate model, respectively (Lin, 1989; King and Chinchilli, 2001; Liao, 2003).

Furthermore, the efficiency of the prediction models was evaluated using the estimate values of the mean square error of prediction (MSEP), root MSEP (RMSEP), and MSEP components such as the squared bias, the systematic error, and the random error. The squared bias represents the central tendency of the error (mean of the deviations). The systematic error represents the error associated with the slope of the regression, and the random error represents the error that was not explained by the model (Bibby and Toutenburg, 1977). The CCC, MSEP, and RMSEP were estimated using the Model Evaluation System (College Station, TX; http://nutritionmodels.tamu. edu/mes.html) as described by Tedeschi (2006).

The proposed prediction model using HG (model [1]) presented a higher correlation coefficient for BW (0.96), followed by WH (0.90) and HH (0.89). Moreover, model [1], which used HG as the single estimator for 
BW prediction, presented the lowest Akaike information criterion (Akaike, 1974) and the lowest Bayesian information criterion. Therefore, HG appeared to be the best predictor, superior to both $\mathrm{WH}$ and $\mathrm{HH}$ (Table 2; Figure 1).

Only model [1], in which HG was the independent variable, predicted values that fit the observed data well $\left(\beta_{0}=0, P=0.91 ; \beta_{1}=1, P=0.76\right.$; Table 3 , Figure 2). The model presented a mean bias of 4.84 $\mathrm{kg}$, which represents an underestimation of $1.9 \%$ of the observed BW. Model [1] accounted for $93.6 \%$ of the variation in $\mathrm{BW}$ and presented the lowest value for RMSEP (5.41\% of observed BW). The major part of the prediction error was associated randomly $(87 \%$ of MSEP), indicating that only $13 \%$ of the error was associated with the model. Model [1] presented the highest proximity of observed BW with the identity line $(\mathrm{Y}=$ $\mathrm{X}$; Figure 2). In addition, model [1] had the highest values of CCC, $\rho$, and $C_{\mathrm{b}}$, indicating greater precision and accuracy. Therefore, the proposed model using HG (model [1]) was considered the only appropriate model for the prediction of BW for dairy heifers.

The model proposed using WH (model [2]) had lower mean bias than model [1] but higher RMSEP due to overestimation of the $\mathrm{BW}<272 \mathrm{~kg}$ and underestimates of BW $>272 \mathrm{~kg}$ (Table 3 ; Figure 2). The proposed model using HH (model [3]) had the highest mean bias (72.02 $\mathrm{kg}$ of BW) and RMSEP (30.83\% of observed BW), with the highest contribution of error due to squared bias among all the models (Table 3). The bias of model [3] increased with increasing BW in heifers (Figure 2).

The model proposed by Heinrichs et al. (1992) using HG ([H1]) produced a significant global bias constant $\left(\beta_{0}=22.84 \mathrm{~kg}\right.$ of $\left.\mathrm{BW} ; P=0.04\right)$, its major limitation. The underestimation was expected because the model was developed for Holstein dairy heifers in the United States (Heinrichs et al., 1992), which appear to have a higher ratio of biometric measurements to BW than crossbred Holstein-Zebu dairy heifers. Although the model proposed by Heinrichs et al. (1992) using WH ([H2]) had the second highest CCC, it overestimated the BW of heifers $>200 \mathrm{~kg}$ (Table 3, Figure 2), demonstrating the inadequacy of $\mathrm{BW}$ prediction for crossbred Holstein-Zebu dairy heifers

The model proposed by Reis et al. (2008) had similar limitations as the HG model of Heinrichs et al. (1992) regarding the global bias constant $\left(\beta_{0}=27.81 \mathrm{~kg}\right.$ of BW; $P=0.017)$. Although the model proposed by Reis et al. (2008) was developed based on measurements of crossbred Holstein-Zebu dairy heifers, its empirical nature represents the main reason for its inadequacy, because it is population dependent. Furthermore, Reis et al. (2008) did not evaluate their model against an independent data set, which remains a limitation for its adoption.

The models to predict BW from measurements of HG or WH proposed by Heinrichs et al. (1992) and the model proposed by Reis et al. (2008) from HG are not suitable for crossbred Holstein-Zebu. The proposed nonlinear allometric model using HG is recommended for predicting the BW of crossbred Holstein-Zebu heifers.

\section{ACKNOWLEDGMENTS}

We thank the Fundação de Amparo a Pesquisa do Estado de Mato Grosso (FAPEMAT, Cuiabá, Brazil) and Federal University of Mato Grosso (Sinop, Brazil) for providing the financial support (project number 483724/2011/PRONEM 006/2011).

\section{REFERENCES}

Akaike, H. 1974. A new look at the statistical identification model. IEEE Trans. Autom. Cont. 19:716-723.

Bibby, J. D., and H. Toutenburg. 1977. Prediction and Improved Estimation in Linear Models. John Wiley \& Sons, Berlin, Germany.

Davis, H. P., W. W. Swett, and W. R. Harvey. 1961. Relation of heart girth to weight in Holsteins and Jerseys. Nebraska Agric. Exp. Stn. Res. Bull. No. 194. Univ. Nebraska, Lincoln.

Diagnóstico da Cadeia Produtiva do Leite do Estado de Mato Grosso. 2011. Relatório de pesquisa. Accessed Apr. 21, 2013. http://www. imea.com.br/upload/Diagnostico_da_Cadeia_do_Leite_MT__Final_.pdf.

Diagnóstico da Pecuária Leiteira do Estado do Minas Gerais. 2005. Relatório de pesquisa. Accessed Apr. 21, 2013. http://www.sebraemg.com.br/bibliotecadigital/documento/Cartilha-Manualou-Livro/Diagnostico-da-Pecuaria-Leiteira-do-Estado-de-MinasGerais-em-2005.

Guimarães, A. V. 2009. Desempenho de bezerras leiteiras alimentadas com farelo de mamona tratado com óxido de cálcio. MS Diss. Universidade Federal de Viçosa, Brazil.

Heinrichs, A. J., G. W. Rogers, and J. B. Cooper. 1992. Predicting body weight and wither height in Holstein heifers using body measurements. J. Dairy Sci. 75:3576-3581.

Heinrichs, J., and B. Lammers. 1998. Monitoring dairy heifer growth. Accessed Apr. 21, 2013. http://pubs.cas.psu.edu/freepubs/pdfs/ ud006.pdf.

King, T. S., and V. M. Chinchilli. 2001. Robust estimator of the concordance correlation coefficient. J. Biopharm. Stat. 11:83-105.

Liao, J. J. Z. 2003. An improved concordance correlation coefficient. Pharm. Stat. 2:253-261.

Lin, L. I. K. 1989. A concordance correlation coefficient to evaluate reproducibility. Biometrics 45:255-268.

Littell, R. C. G. A., W. W. Milliken, R. D. Stroup, R. D. Wolfinger, and O. Schabenberger. 2006. SAS for Mixed Models. 2nd ed. SAS Institute, Inc. Cary, NC.

Miranda, L. F., A. C. Queiroz, S. C. Valadares, P. R. Filho, E. S. Cecon, M. F. Pereira, J. M. S. Paulino, S. C. Campos, and J. R. Miranda. 1999. Performance and ponderal development of dairy heifers fed sugar cane based diets. Rev. Bras. Zootec. 28:605-613.

Neter, J., M. H. Kutner, C. J. Nachtsheim, and W. Wasserman. 1996. Applied Linear Statistical Models. 4th ed. McGraw-Hill, New York, NY.

NRC. 2001. Nutrient Requirements of Dairy Cattle. 7th rev. ed. Natl. Acad. Press, Washington, DC. 
Reis, G. L., F. H. M. A. R. Albuquerque, B. D. Valente, G. A. Martins, R. L. Teodoro, M. B. D. Ferreira, J. B. N. Monteiro, M. A. Silva, and F. E. Madalena. 2008. Prediction of live weight based on body measurements in crossbred animals Holstein/Gir. Cienc. Rural. 38:778-783.

Santos, S. A., J. M. S. Campos, S. C. Valadares Filho, E. Detmann, A. S. Oliveira, and S. M. Souza. 2010. Productive performance of growing dairy heifers fed corn silage and soybean or cottonseed meal based concentrate. Rev. Bras. Zootec. 39:639-647.
St-Pierre, N. R. 2001. Invited review: Integrating quantitative findings from multiple studies using mixed model methodology. J. Dairy Sci. 84:741-755.

Tedeschi, L. O. 2006. Assessment of the adequacy of mathematical models. Agric. Syst. 89:225-247.

Vidaurre, M. B. 2009. Cana-de-açúcar in natura ou armazenada, corrigida com uréia, na alimentação de bovinos leiteiros em crescimento. MS Diss. Universidade Federal de Viçosa, Viçosa, Brazil. 